
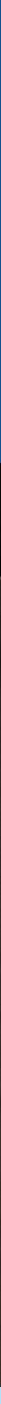

\title{
Agenda 2030 and SDGs at the local level-a brief start-up guide
}

The Nordic countries are often placed at the top of global rankings on sustainable development. Well-established democratic systems are in place to fight poverty, promote economic growth and ensure gender equality, as well as to protect the environment and peace and justice.

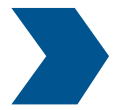

Much of the success of the Nordic Region stems from the local system of governance, under which many decisions are taken in local democratic forums. In the Nordic countries, municipalities are the most local form of official public authority with elected politicians. In many ways, municipalities and regions support the wellbeing of our everyday lives in the Nordic Region. They provide public services such as infrastructure, waste treatment and social services. Therefore, local and regional authorities are key to the overall successful implementation of the sustainability ambitions 
established at other government levels. A change towards sustainable development will not occur without the commitment of the local and regional governments.

In October 2019, the Nordic Council of Ministers organised an event in Stockholm for Nordic municipalities and other local authorities to meet and exchange their experiences in working with Sustainable Development Goals (SDGs). This policy brief provides a synthesis of the conclusions from that event, the findings from a previous study on the topic (Sánchez Gassen et al., 2018) and the authors' experience within the sustainability field (Slätmo, 2017). The intention is to highlight the key lessons learned from the different stages of the SDG process, considering the three dimensions-environmental, social and economic-of sustainability. Although we consider how local and regional authorities in the Nordic countries work, our content is informative for any type of organisation, regardless of whether it is public, private or voluntary.

\section{A SUSTAINABLE PROCESS}

One suggestion for ensuring the implementation of Agenda 2030 as a sustainable process is to conceive of it as an ongoing process with regular updates of goals, activities and measures. In the following sections, we present the process divided into starting, implementation and follow-up phases. These three overlapping phases are a means to create a sustainable process.

\section{How to get started}

Leadership is crucial regardless of whether an organisation is public, private or voluntary. There must be a vision with which the whole organisation is familiar. One way to get started is to examine the organisation and identify the activities that already contribute to SDGs even if they are not necessarily labelled as such. For instance, such activities may include the mandatory tasks of municipalities and regions in providing education, health care and infrastructure. Asking the questions 'How do we work with sustainability?' and 'How could we fit the SDGs into our work?' is a good start. This form of self-assessment could 'jump-start' the process of integrating the SDGs into existing vision and plans.

The results from such an exercise can be used to commence a participatory and iterative process to develop an adapted vision and strategy. The participatory work can be conducted using workshops and other forms of small or large meetings. Nordic local authorities often use public places for meetings, such as libraries, schools and museums, or other local and regional authority buildings. Ensuring the involvement of others in society, not just management, is important to provide a broad range of perspectives and to contribute to the legitimacy of the next phases; implementation and follow-up.

\section{How to implement SDGs}

The results from Nordregio (Sánchez Gassen et al., 2018) show that some Nordic local authorities follow what we describe as a holistic approach to the SDGs. This implies that the SDGs are used to 'mainstream' the sustainability perspective across all administrative levels, sectors and activities. Others use a more targeted approach in working with the SDGs, which implies that the SDGs are incorporated into specific projects or policy areas, or used for specific purposes.

\section{How to monitor and follow up}

Without annual monitoring and evaluation, it is not possible to ensure that the organisation is on the right track towards the vision and goals. Most organisations that have been involved in the work of Nordregio state that they follow up on their work on sustainability or the SDGs. The results from the evaluation and goal fulfilment steps are used to focus on the work done in the organisation. The follow-up phase is important to ensure the organisation keeps up the pace and does not lose focus.

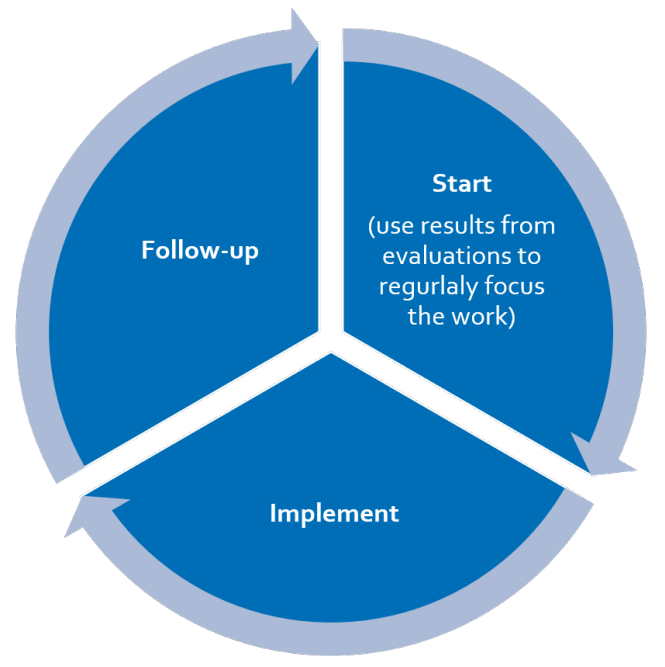

Some local authorities have stated that they want to measure progress compared with other cities, regions, local authorities or businesses. A range of different institutions and companies are currently developing a common indicator framework for this purpose and several indicator tools and benchmarks are available globally. The wide range of tools makes it challenging to compare and benchmark organisations.

It also makes choosing the right tool difficult from the perspective of the local and regional authorities. Using the predefined SDG indicators is perceived as complicated at the local level (given that there are 169 indicators for the 17 SDGs). The local authorities at the knowledge-sharing event in October 2019 indicated that they do not regard such a complicated follow-up system as useful. Some local authorities even stated that comparing themselves with others is not a priority because they work for the politicians and people in their local area and do not view such comparisons as their responsibility. It was also stated 


\section{Below, we provide a check-list of necessary steps towards implementing Agenda 2030 internally:}

00000000000000000000000000000000000000000000000

- Assess how your organisation works with sustainability.

One way to begin is to examine the organisation and identify the activities that already contribute to SDGs even if they are not necessarily labelled as such. Ask yourself 'How do we work with sustainability?' and 'How could we fit the SDGs into that work?'

Use the self-assessment as the starting point for a participatory process. Involving others in society, not just management, is important to ensure the inclusion of the broad range of perspectives that constitute society, as well as to ensure the legitimacy of the process.

Decide how many SDGs should be prioritised. Based on the self-assessment and participatory dialogues, determine whether you want to use a holistic approach or a targeted approach to implementation. This choice can be included in a locally or regionally adapted vision and strategy.

Decide where in the organisation responsibility for the work on Agenda 2030 and SDGs should be placed. Responsibilities and mandates must be divided and communicated clearly throughout the organisation.

Determine how to integrate SDGs into key steering documents. Do you need to change or create new routines for your work and organisation? These could be related to reporting as well as other functions. Ensure all levels of the organisation are on board and that the decisions are communicated clearly within the organisation.
Decide upon funding. Should the SDGs be regarded as a new budget entity or be part of already existing budgets? The integration of the SDGs into the budget of the whole organisation or of the specific departments responsible for the work must be decided on and communicated clearly throughout the organisation.

Decide on how to follow up. Regardless of whether you choose to work with a few SDGs (a targeted approach) or to implement Agenda 2030 holistically, it is important to follow up progress to ensure that you avoid creating conflicts and instead focus on the synergies between the SDGs. The overarching questions to ask when determining indicators, success criteria or milestones are: 'How do we know that we are on the right track?' and 'How do we know that our activities make a difference?'. Note that involving others in a participatory process can be of help to answer the second question, see the section above on 'How to get started'.

Implement the work you have decided upon. If you have followed the previous steps, the work with the SDGs and Agenda 2030 is already linked to the mandatory tasks in the organisation. For inspiration on how Nordic municipalities have implemented Agenda 2030 and the SDGs, see the section below on 'Sustainable outcomes from Nordic municipalities and regions'.

Communicate the work done internally and externally. In dialogue with the organisation, establish a plan to determine how to regularly communicate your work on sustainability. 


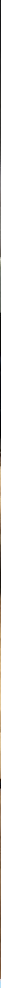

Dialogue and face-to-face meetings are important to obtain input on new ideas and to anchor the work within the organisation and society. Picture from the Agenda 2030 event in Stockholm, October 2019.

that using an indicator framework developed by someone external to the organisation may reduce or eliminate the local creativity of the work with Agenda 2030 and the SDGs.

In this context, it is relevant to acknowledge the need for cross-Nordic co-ordination to ensure that progress is measured in a way that is relevant and useful for the local and regional levels.

\section{Sustainable outcomes from Nordic municipalities and regions}

Agenda 2030 highlights the three dimensions of sustainability: environmental, social and economic. However, the 17 SDGs are not formulated as belonging to one of these sustainability dimensions. Instead, the SDGs are formulated to be implemented across sectors within an organisation and using a multiactor approach across governance levels. Therefore, public, private and civil society actors (on the local, regional, national and multilateral institutional levels) need to contribute to the SDGs based on their respective roles and their capacity to undertake the work. Not everyone can do everything, but everyone can do something.

In the sections below, the traditional sustainability dimensions are used to highlight how Nordic municipalities and regions will work to fulfil Agenda 2030, the SDGs and the vision of the Nordic Council of Ministers that the Nordic Region will become the most sustainable and integrated region in the world by 2030 (NCM, 2019).

\section{Environmental sustainability}

Environmental sustainability is about the green transition of our societies and working towards carbon neutrality and a sustainable circular and bio- based economy (NCM, 2019). Climate Action (SDG13) and Affordable Clean Energy (SDG7) were the focus at the knowledge-sharing event in 2019.

A spatial planning initiative for Affordable Clean Energy (SDG7) aims to ensure smart and integrated solutions by locating heat-demanding close to colddemanding premises, e.g., an ice rink close to a swimming pool is for instance found in Göteborg, Sweden. By such a co-location the cooling and heating systems for the premises can be integrated for optimal use of energy. In addition, investment models that ensure that the capital invested is retained in the local or regional areas are being used to enhance investments in fossil-free energy forms, such as windmills.

Regarding Climate Actions (SDG13), the participants at the knowledge-sharing event in October 2019 highlighted that measures for climate mitigation have long been a focus, whereas the focus on adaptation is relatively new, and has been strengthened by the frequent fluctuations between weather extremes. In concrete ways, the work with Climate Action is occurring through 'mainstreaming' environment-friendly options and 'nudging' citizens towards these. For instance, actions include the provision of climate-friendly mobility options and operations (cycling, public transport, carpooling and remote working). An innovative action occurring in Pirkkala, Finland, is an assessment of potential carbon sinks (non-built up land, farm-land, forestry and green areas) as a basis for decisions in spatial planning.

\section{Social sustainability}

The work towards social sustainability promotes an inclusive, equal and interconnected region with shared values and strengthened cultural exchange 


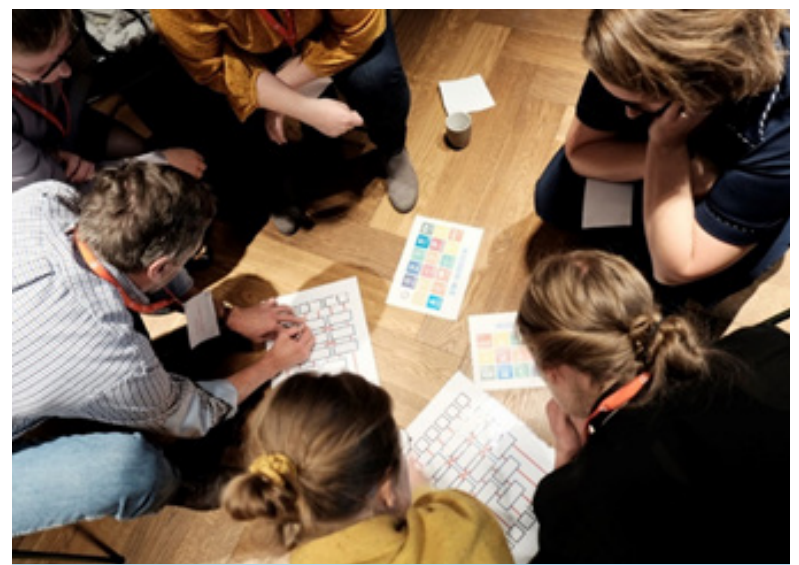

Working together in mixed groups assists in determining innovative ways to manage organisations and societies.

and welfare (NCM, 2019). Gender Equality (SDG5) and Peace, Justice and Strong Institutions (SDG16) were in focus at the knowledge-sharing event in 2019.

It was highlighted that more knowledge and awareness on how to work with Gender Equality (SDG5) in spatial planning is necessary. To fulfil SDG5, it is important to take a broader system perspective to understand possible effects arising from policy decisions. This requires measures beyond the 'tick box' of setting appropriate female-to-male ratios in project groups. Some local authorities are actively working to quantify the gendered effects of decisions. For instance, Umeå, Sweden, calculate how different gender groups gain from investments in spatial planning.

The actors at the knowledge-sharing event highlighted that the work with Peace, Justice and Strong Institutions (SDG16) is linked to issues of wellbeing, democracy and youth. Trust in institutions is crucial to fulfilling the SDG, and one approach is to focus on well-being because if people feel well, they are more likely to feel trust in other people and in authorities. To strengthen democracy in the Nordic Region, the perceptions of an unfair division between urban and rural areas that were highlighted need to be addressed. It is important to continue to talk to each other about this issue, to conduct analyses on the distribution of investments in different urban and rural regions and to inform inhabitants about the Nordic democratic model concerning how decisions are made. Involving young people, who are the future, is crucial in the work towards sustainability and incorporating their perspectives in decision-making is especially important.

\section{Economic sustainability}

Economic sustainability facilitates green growth in the Nordic Region based on knowledge, innovation, mobility and digital integration (NCM, 2019). Decent Work and Economic Growth (SDG8) and Responsible
Consumption and Production (SDG12) were in focus at the knowledge-sharing event in 2019.

While discussing Decent Work and Economic Growth (SDG8), it was highlighted that actors in the public sector have a broader perspective on the economy compared with actors in private businesses. In this context, the importance of having a competent workforce was highlighted as crucial to fulfilment of SDG8. Furthermore, it is important to be realistic about the capacity of local authorities. It is important to engage different intermediaries, such as chambers of commerce, company networks and regional level organisations, to support sustainable enterprises and develop a competent workforce. The regionallevel governments could take on a more robust role or communicate more clearly what they are doing to support the local authorities regarding a competent workforce and supporting the local economy.

The discussion of Responsible Consumption and Production (SDG12) circulated around the possibilities for the public sector to lead the way for businesses through its public procurements. The public sector is an important market for businesses. To strengthen local and regional business, public authorities can invite local businesses to discuss procurements. Such meetings can help the public sector realise what they can expect from suppliers in the private sector and, if businesses are more advanced in the development of sustainable solutions, the meetings also provide an opportunity for the businesses to influence what the public sector specifies in the conditions for procurements.

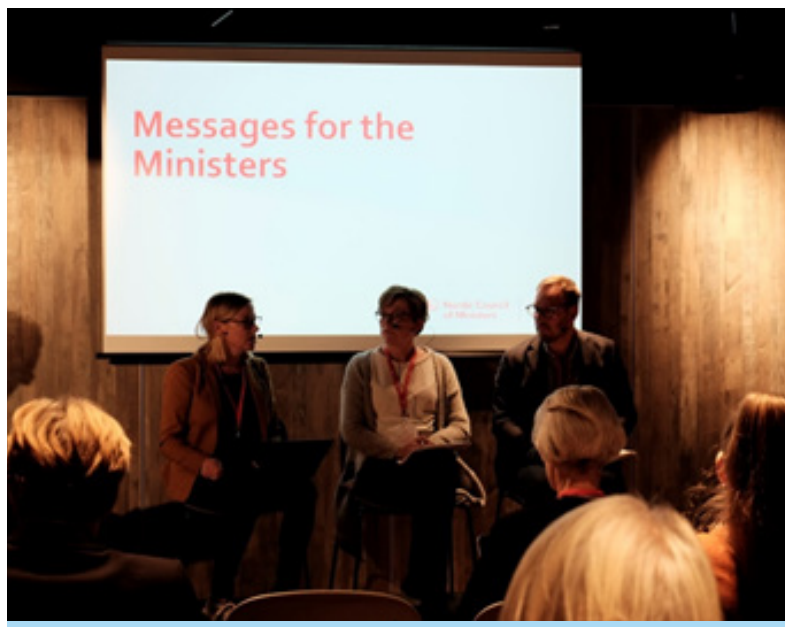

One of the messages for the ministers from the panel summarising the knowledge-sharing event on 28 October 2019 is: 'Brave politicians and brave civil servants, that is something we really need. An open mind to try new ways of managing societies and municipalities'. 


\section{Recommended next steps}

Based on the discussions at the event in October 2019, we recommend the following next steps to maintain the pace of the sustainability work in the Nordic Region.

00000000000000000000000000000000000000000000000

The Nordic Council of Ministers and/or notional governments could: - provide annual opportunities for knowledge-sharing between local and regional authorities within the Nordic Region.

- clarify to municipalities, regions and cities which SDGs are the focus in the Nordic Region.

- help raise awareness of the fact that specific priorities, implementation actions and impact assessments are dependent on local conditions and activities.

- improve relations between politicians and administrations, with councillors requesting assessments of outcomes and results of SDG-related activities to encourage the administration.

- recommend that all municipalities in the Nordic Region to include the SDGs in their work. This would need to be coupled with good examples and an SDG checklist.

- ensure cross-Nordic co-ordination in measuring the outcomes of the work concerning the Agenda 2030 and the SDGs. The desire for benchmarking and developing indicators on SDG progress expressed by a range of actors must be balanced against the risk of restraining creativity regarding sustainability actions at the regional and local levels.

- provide knowledge to local and regional authorities on how to include gender in spatial planning and other mandatory tasks (SDG5).

- strengthen democracy in the Nordic Region by informing people about how the political systems in the region function (SDG16).
- address the widespread perception of an unfair division between urban and rural areas in the Nordic Region (SDG16).

- involve children and youth in the process of implementing Agenda 2030 (SDG16).

\section{negional authorities could:}

- share good examples and solutions for inspiration, but also tell stories of failure so that local authorities can learn from the mistakes and problem-solving skills of others.

- improve relations between politicians and administrations, with councillors requesting assessments of outcomes and results of SDG-related activities to encourage the administration.

- arrange for more regional agreements for co-operation between municipalities regarding land and water use (SDG13).

- take on a more robust role and communicate more clearly to local authorities what is done to support them regarding sustainable enterprises, local economies, procurements and developing a competent workforce (SDG8).

- invite regional businesses to discuss procurements. Such meetings can assist the public sector to realise what they can expect from suppliers in the private sector. In addition, if businesses are ahead in the development of sustainable solutions, the meetings can provide an opportunity for them to influence what the public sector specifies in the conditions for procurements (SDG12).

- involve children and youth in the process of implementing Agenda 2030 (SDG16). 


\section{- Local authorities could:}

- continue to be creative in the work with Agenda 2030 and SDGs.

- improve relations between local politicians and administrations, with councillors requesting assessments of outcomes and results of SDGrelated activities to encourage the administration.

- continue to 'mainstream' climate and environment-friendly options and 'nudge' citizens towards them (SDG13 and SDG7).
- invite local businesses to discuss procurements. Such meetings can help the public sector realise what they can expect from suppliers in the private sector. Where businesses are ahead in the development of sustainable solutions, such meetings also provide an opportunity for the businesses to influence what the public sector specifies in the conditions for procurements (SDG12).

- involve children and youth in the process of implementing Agenda 2030 (SDG16).

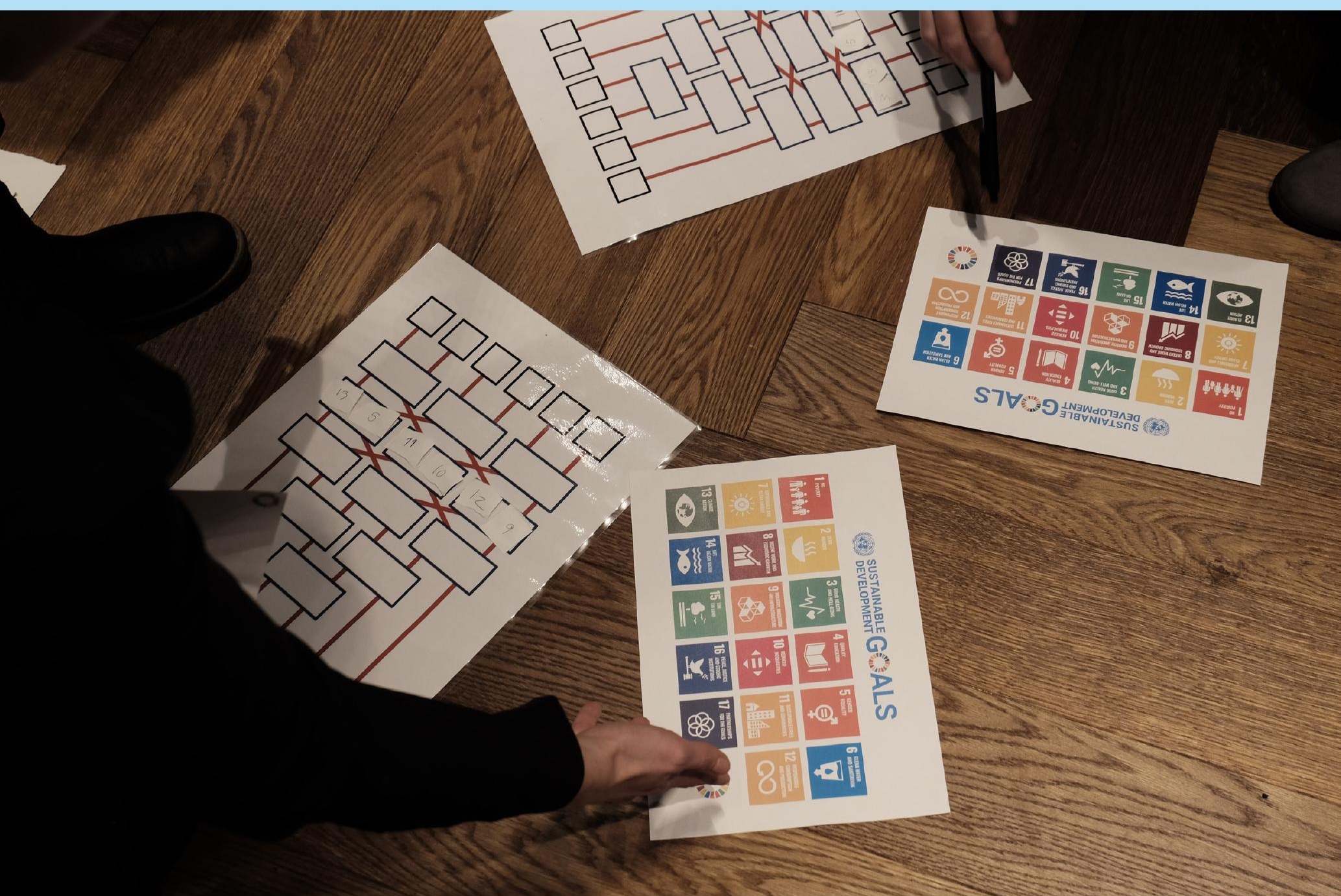


